\title{
Liaison Psychiatry in a Spinal Injuries Unit
}

Fiona K. Judd, M.B., B.S., DPM ${ }^{1}$ and Graham D. Burrows, M.D., Ch.B., B.Sc., D.P.M., F.R.A.N.Z.C.P., F.R.C.Psych. ${ }^{2}$

${ }^{1}$ Liaison Psychiatry Registrar. ${ }^{2}$ Professor of Psychiatry and Liaison Psychiatrist, Spinal Injuries Unit, The Austin Hospital, Heidelberg, Victoria 3084, Australia.

\section{Summary}

Spinal cord injury may produce both immediate and long term stress and disability. The liaison psychiatrist may have an important role in dealing with the problems of the spinal cord injured patient, his family and the medical team. Problems occurring may cause or be exacerbated by psychological difficulties. Problems occurring during rehabilitation and long term adjustment have not been systematically studied. Many assumptions concerning the psychological responses to injury have been made. Such assumptions have important implications for both the short and long term treatment of patients. This paper examines some of these areas.

Key words: Liaison psychiatry; Psychological response to spinal cord injury.

\section{Introduction}

Consultation liaison psychiatry has developed as an outgrowth of general hospital psychiatric units. Liaison psychiatry is based on the psychosomatic approach. It is founded in the assumption that human health and disease are the result of the interaction of biological, psychological and social factors. The focus is on individuals whose psychiatric problems are related to physical illness and disability.

The term 'consultation liaison' emphasises two distinct but related processes (Lipowski, 1974). Consultation refers to assessment and advice regarding treatment of a particular patient. Liaison indicates a broader therapeutic role in which the psychiatrist becomes an accepted member of the medical team. The liaison psychiatrist has both a preventative and therapeutic role. He interprets the attitudes and behaviour of patients and the medical team, and mediates between patients and other therapists or between members of the medical team. This role allows the psychiatrist to identify and allay conflicts, explain contentious issues and facilitate communication. Optimal patient care includes accurate diagnosis,

Correspondence to Dr. F. K. Judd, Department of Psychiatry, Austin Hospital, Heidelberg, Victoria 3084, Australia. 
appropriate treatment including rehabilitation, and prevention or reduction of psychiatric morbidity. These different roles are highlighted when dealing with the many severe problems of the spinal cord injured patient, his family and the medical team.

Diagnostic problems encountered in consultation liaison psychiatry may be divided into several broad categories (Lipowski, 1974). The patient may complain of somatic symptoms for which no organic cause can be found. This may be the result of a discrete psychiatric illness such as depression, or psychosocial stresses. Patients may be referred for pyschiatric assessment following changes in habitual behaviour. This may occur in the presence of organic cerebral disease, functional psychiatric illness, psychosocial stress or as a response to physical illness. Patients displaying varieties of abnormal illness behaviour including denial of illness, noncompliance, excessive dependency, are frequently referred. Advice regarding treatment of obvious psychiatric illness may be sought.

Spinal cord injury may produce both immediate and long term stress and disability. Problems may cause or be exacerbated by psychological difficulties. This paper provides an overview of the literature describing psychological problems in spinal cord injured patients.

\section{The spinal injuries unit epidemiology}

Over $60 \%$ of spinal injuries occur to persons aged 15 to 29 years old (Trieschmann, 1981). Motor vehicle accident is the most frequent cause of spinal injury. Sporting injuries more frequently produce tetraplegia than paraplegia. Most often this is due to diving, surfing and skiing accidents. Males account for $82 \%$ of spinal injuries, females for $18 \%$, (Trieschmann, 1981). Falls are the primary cause of spinal injury in the over 60 years age group.

\section{Immediate responses to spinal cord injury}

\section{Awareness of injury}

Not all individuals who suffer a spinal cord injury are aware of an inability to move at the time of the accident. Heilporn and Noel (1968) suggested only $50 \%$ were initially aware of a disability. Usually, initial awareness of the accident and its sequelae is followed by a variable period in which the individual is unaware of what occurs around him. This may be a psychological defence which protects the individual from too rapid a perception of the overwhelming situation (Gunther, 1969). Anaesthesia, analgesia, accompanying physical illness and injury, pain and physical shock to the individual may contribute. Thirty per cent of patients with serious traumatic spinal injury have significant associated injuries (Harris, et al., 1973).

\section{Anxieties}

Clinical experience shows that frequently survival is the major concern of patients and families. This is particularly so in patients with high cervical lesions or those with associated chest injuries who require ventilator support of respiration. Other 
common sources of anxiety in the early post-injury phase include fear that pain will persist, and panic following the abrupt loss of sensation over most of the body. Lack of information about what is happening may be particularly frightening.

\section{Impaired conscious state}

Sensory deprivation may be severe in the initial period of hospitalisation. Altered sensory input from the body, restriction of movement and isolation in the hospital ward, may profoundly influence the injured person's behaviour. Those persons with tetraplegia, with head tongs to immobilise the neck, have both less possible movement than a paraplegic patient and a more restricted visual field. Further perceptual restriction results from monotony of the hospital routine and lack of intellectual activity. (Soloman and Kleeman, 1985).

Characteristic features of sensory deprivation include anxiety, tension, inability to concentrate and organise one's thoughts, and increased suggestibility. More severe reactions are characterised by vivid sensory, usual visual imagery. Less often, hallucinations and delusions may occur.

Many other factors may contribute to impairment of mental function in the first days or weeks of treatment. Lack of cues to identify the passage of time may result in disorientation in time and place. Inadequate respiratory function may produce hypoxia. Associated injuries and treatment of these, particularly analgesic medication, may reduce the conscious state. Intensive medical care results in sleep deprivation which further impairs mental function. Pain interferes with concentration. The elderly patient is particularly at risk for development of a confusional state.

\section{Psychological responses to spinal cord injury}

Psychological reactions to physical illness are influenced by a number of factors. Acute and chronic physical illnesses affect individuals in different ways. Factors which influence the patient's psychological response to acute illness may be divided into three broad groups (Verwoerdt, 1972). Important variables in the illness itself include severity of symptoms, degree of disability, perceived threat to life, duration and rate of progression of illness and the particular body part affected. Patient variables include age, sex, body image, premorbid personality and coping mechanisms. The patient's family, social and employment environment may also significantly influence his response to illness.

The severity of stress caused by illness is also influenced by intra-psychic factors. Engel (1962) classified stress in terms of loss or threat of loss of psychic objects, injury or threat of injury, and frustration of drives and drive derivatives. This classification emphasises that the illness stress is defined not only in terms of the external effects of the illness but also by what is experienced intrapsychically. The intra-psychic experience is determined by past experiences and stresses and particularly by unresolved intra-pyschic conflicts.

Object loss as defined by Engel, may be real, threatened or fantasied. Such loss may include loss of part of the body or body function, loss of membership or status of a social or professional group, loss of future plans, home, personal possessions, job, profession or occupation. Physical illness is particularly experienced as a loss when it interferes with social or occupational functioning and social status, or 
impairs particular skills and talents. Spinal cord injury affects many of these areas.

Strain and Gross (1975) described several other categories of psychological stress frequently experienced by patients with physical illness or injury. These are the basic threat to narcisistic integrity; fear of strangers; separation anxiety, fear of loss of love and approval; fear of loss of control of developmentally achieved functions, e.g. bladder and bowel control; fear of loss of or injury to body parts (castration anxiety); and reactivation of feelings of guilt and shame and accompanying fears of retaliation for previous transgressions. The patient with a spinal cord injury may experience any or all of these.

The literature discussing adjustment to spinal cord injury is contradictory. A number of writers have described distinct but different stages of adjustment. No controlled studies have documented the existence of these stages, or assessed their frequency. Some authors state denial is the first and most profound response to injury (Witthower, et al. 1954). Others suggest anxiety and depression are the most prominent responses (Siller 1969). Other commonly described behaviours occurring in the first three to six months after injury include anger and rebellion, impulsiveness, explosiveness, ambivalence, passive submissive and dependent behaviour (Kerr and Thompson, 1972; Berger and Garrett, 1952).

Many authors have described the response to spinal cord injury within the grief model. For example, Hohmann (1975) suggested initially the response is denial usually lasting 3 weeks to 3 months. Denial in the early post injury phase is presumed to be both adaptive and protective. When denial interferes with realistic plans for care and discharge, it is maladaptive. Maladaptive denial is often expressed in actions rather than words. Inattention to pressure and bladder care are common manifestations of this.

According to the grief model, as described by Hohman, resolution of denial is followed by depression. This may be manifested as withdrawal and internalised hostility. The patient may express suicidal ideation. Feelings of futility, lack of motivation and feelings of guilt and uselessness may be severe. The patient may attempt to dissociate himself from the family. Married patients may suggest divorce. Later, hostility may be externalised onto those around the patient. Doctors, family and friends may be blamed for the injury. Patients may be hostile and demanding. Physical and verbal aggression may be prominent.

The final stage has been described as a reaction against dependence. The patient may reject rehabilitation and assistance and attempt to convince himself of his self-sufficiency. After these phases are worked through, pre-injury personality and means of coping with stress become prominent and intensification of pre-injury traits may be evident. The irresponsible patient may become more so, the conscientious, responsible patient may intensify these characteristics in an attempt to compensate for his disability.

While use of the grief model is of heuristic value, a number of differences between the bereaved and the spinally injured should be noted. Until systematic studies reliably define such phases clinicians should not presume patients will react this way, and that this reaction is normal.

\section{Factors associated with adjustment to spinal injury}

A number of studies have attempted to identify the characteristics associated with 
successful adjustment to spinal cord injury. Major methodological problems exist. Different definitions of adjustment are used or the definition used is not specified. Patients with paraplegia and tetraplegia are assessed together. Confounding variables such as head injury, interpersonal problems, and pre-existing psychopathology are not considered.

Available data suggest that younger patients, especially those less than 45 adjust better to spinal injury than do older patients (Kemp and Vash, 1971, Kerr and Thompson, 1972, Wilcox and Stauffer 1972). Woodrich and Patterson (1983) found females to be more accepting of their disability than males. Pre-injury educational and occupational attainment and theoretical interests (Nickerson 1974), satisfactory pre-injury life history (Kerr and Thompson 1972) and supportive interpersonal relationships (Kemp and Vash 1971, Kerr and Thompson, 1972) have been identified as predictive of good outcome.

Premorbid personality may also influence the manner in which individuals cope with their injury. High ego-strength, ability to delay gratification (Roberts, 1976) and conscientiousness (Witthower, et al. 1954) are more often associated with good adjustment to injury. Those with little personal effort and ambition (Thorn, et al., 1964) or with psychopathic traits (Mueller and Thompson, 1950; Nagler, 1950; Guttmann, 1976) often cope poorly. Passive personality traits may predict compliance in rehabilitation and avoidance of risk taking behaviour (Siller, 1969). Such individuals may have difficulty re-establishing an independent life style and require longer term assistance with adjustment.

\section{Depressive illness following spinal cord injury}

The incidence of depressive illness following spinal cord injury is unknown. It is commonly assumed that most patients with traumatic paraplegia or tetraplegia eventually experience depression (Bracken \& Shepherd, 1980; Stewart, 1977a; Witthower, et al., 1954). Some investigators believe depression is inevitable (Hohmann, 1975; Stewart, 1977b). Depression is regarded by many as a normal phenomenon, part of the phasic response to spinal cord injury.

Confusion of despondency and depression may result in reports of universal depression in patients with spinal cord injury. Despondency is a common reaction to serious illness but is generally brief, non-pervasive and not accompanied by many vegetative, cognitive and behavioural symptoms. Further difficulties may result from failure to differentiate depressive illness from grief. Grief is the complex emotional response to loss. It may include anxiety, sadness, anger, guilt, hopelessness and despair. The typical grief response comprises a number of phases including a period of stunned disbelief, angry protest, yearning and pining for a return of what was lost, and despair. Partial or total absence, or distortion of the grief response, may predispose to the development of a pathological grief reaction or the onset of a depressive illness. In contrast to despondency and grief, depression is characterised by sustained lowered mood which is qualitatively different from normal, sleep and appetite disturbance and change in psychomotor function.

The nature of spinal cord injury itself results in problems of diagnosis. Sensory deprivation and insufficient arousal may result in lethargy and disinterest in the early post injury stages (Richards, et al., 1982). Patients may withdraw into the 
conservation-withdrawal response to protect themselves from being overwhelmed by the many disruptions of the treatment programme (Weiner and Lovitt, 1979). These conditions may mimick, but should be differentiated from, depression.

Few studies systematically assessing the incidence of depressive illness exist. Lawson (1978) studying 10 patients with tetraplegia for their entire hospital stay (mean stay 109 days), found no clear periods of depressive affect. Fullerton, et al. (1981) studied fifteen paraplegic and fifteen tetraplegic patients with spinal cord injury. Psychiatric diagnoses were made using the Schedule for Affective Disorders and Schizophrenia (S.A.D.S.) and the Research Diagnostic Criteria (R.D.C.). Fifteen patients had no R.D.C. diagnosis prior to or following injury. Nine patients were depressed after injury. Depression was not an extension of pre-injury problems, but developed after injury. Eight depressive disorders developed within one month of injury. One did not become depressed until 3 months after injury.

Many of the physical consequences of spinal cord injury and its treatment mimick the symptoms of depressive illness. The validity of the use of traditional interview schedules and operational diagnostic criteria in these patients is not established. Studies to determine the incidence of depression in these patients must address these problems.

\section{Body image disturbance}

Body image refers to the individual's feelings and attitudes to his own body, body parts and body function. Bors (1951) found distortion of body image in $100 \%$ of patients studied. All patients described phantom limb phenomena involving either cutaneous sensations or postural hallucinations. Most commonly patients describe disturbance of proprioceptive body image (Conomy, 1973). Commonly, patients feel their legs are positioned in other than their visually perceived location. These disorders most often affect the lower limbs. Disordered perception of posture or movement, kinetic body image, and disorders of perception of somatic size, bulk and continuity are also frequent. Patients frequently do not discuss these experiences and often find them terrifying. Some patients fear that hallucinatory phenomena are a manifestation of psychiatric illness (Conomy, 1973). The anatomical basis for disorders of body image following spinal cord injury is not clear.

\section{Pain}

Pain at the site of trauma usually lasts only for a few weeks. If instability of the vertebral column persists, movement may cause pain. Damaged facet joints may become arthritic, and instability of movement may result in chronic pain.

Spinal cord injury may be complicated by four distinct types of neurogenic pain (Hohmann, 1975). Phantom sensations commonly occur in the early stages of injury. These are not usually painful. Secondly, burning-tingling sensations are described by almost all spinal cord injury patients. These dysasthesias are influenced by numerous factors including depression, anxiety, alcohol excess, marijuana and cigarette smoking, exercise and fatigue (Davis, 1975). Thirdly, 
radicular pain may occur in the first few weeks after injury. Nerve roots may be compressed or torn. Adhesive arachnoiditis may produce prolonged radicular pain. This pain has a dermatomal distribution in the transitional zone between sensation and anaesthesia. Often there is a band of hyperaesthesia. Cervical, upper and mid-thoracic lesions affect only a few nerve roots. In the lower thoracic and lumbo-sacral areas many roots may be affected and pain may be felt in a wide area of the trunk and lower extremities. Finally, causalgia-like pain is described by some patients with cauda-equina or incomplete lesions. It is frequently described as shooting or electric pain.

Chronic pain is common in patients with spinal cord injury. Pain may occur, be prolonged or exacerbated for psychological reasons (Elton, et al., 1983). There are three principal mechanisms for the psychological aetiology of pain. Most often, pain is due to muscle tension, often the result of psychological factors. Less frequently, pain may be a hysterical conversion symptom, or may occur as a hallucination. Engel (1959) described a group of patients who experienced pain with unusual intensity or frequency, often without any peripheral pain process. Psychological factors play a primary role in the aetiology of pain in these 'painprone patients'. For these patients, guilt is an invariable factor in the choice of pain as a symptom. Patients with chronic pain are often depressed. Frequently they display marked hypochondrial pre-occupation and tend to deny life problems (Pilowsky \& Bassett, 1982). Chronic pain is often reinforced by multiple secondary gains including care from spouse, compensation and relief of responsibilities.

\section{Suicide and self neglect}

Suicide and self-neglect are not uncommon long term problems. Follow-up studies have shown $50 \%$ of patients with spinal cord injury describe suicidal thoughts (Pinkerton, et al., 1983). The suicide rate for the disabled is greater than that for the general population (Hopkins, 1971). In a follow-up study of 423 consecutive patients treated for spinal cord injury, Wilcox and Stauffer (1972) found suicide or self neglect accounted for $43 \%$ of the 50 deaths recorded. Twelve per cent of U.S. veterans with traumatic spinal injuries during the period 1946-1965 died by suicide (Nyquist and Bors, 1967). Most suicides occurred within the first five years of injury. Older and unmarried individuals were most at risk.

\section{Delay in adjustment}

Many clinicians working in spinal injury units believe patients do not adjust to their injury for 1-2 years. Several reports in the literature express similar ideas. Stewart (1977b) has suggested that, following appropriate grieving for loss of physical and associated social functioning, the spinal cord injured patient must develop a modified identity. He has likened the delay in this to the time taken for the development of a sense of identity in adolescence (Erickson, 1965). He suggests this process may require years. Inter-personal, sexual and vocational behaviour cannot reach their full potential until after this period. This moratorium has been stressed by other writers (Cogswell, 1968, Felton and Litman, 1965). 
No longitudinal studies to refute or support these beliefs are available. The high rate of suicide and self neglect reported, together with lack of adjustment and return to normal functioning, may indicate that dysphoric feelings and lack of motivation frequently reported are not simply part of normal adjustment but symptoms of a depressive illness, unrecognised and thus untreated.

Controlled studies to test these hypotheses are needed.

\section{The family of the spinal cord injured patient}

\section{Family responses}

Major adaptive changes are required in families of spinal cord injured patients. Special coping mechanisms are required to deal with the acute and long term effects of spinal cord injury (Steinglass, et al., 1982).

Initially, family members experience a sense of relief that the patient is alive. Attention is focused on the development of relationships with medical staff and the acquisition of knowledge about recovery and rehabilitation. During the recovery phase, the family must adjust to accepting the patient as permanently different. During this time, patients may project angry and frustrated feelings onto the family. Family members may feel alienated from the patient. Guilty wishes that the patient had died may be prominent. Growing realisation of the restricting aspects of the long term disability occurs. Acknowledgement that it is the family not just the patient who is disabled may produce marked anger and resentment. Long term problems may arise when developmental issues within the family are neglected because priority is given to the family's adjustment to chronic illness (Steinglass, et al., 1982).

\section{Marriage}

Studies suggest pre-injury marriages have a relatively high rate of divorce (Siller, 1969; Kaplan, et al., 1966). Divorce is generally attributed to the wide number of changes caused by the spinal cord injury. Change in sexual function does not seem to be a major determining factor (Comarr, 1962). A recent Australian study found only 15 of the total 166 patients followed up after spinal cord injury were divorced (Richards, 1982). This study did not specify the time between injury and follow up.

Marriages occurring after the injury appear to more often succeed than preinjury marriages (Comarr, 1962; Guttmann, 1964-65). Crewe, et al. (1979) compared pre-injury and post-injury marriages in 55 spinal cord injury patients. Those married after injury were happier, more independent, more often employed and more often sexually active than patients who married before injury.

\section{Children}

Little information is available regarding the effect of parental disability on children. Turk, et al. (1983) suggested that the paraplegic woman who has been successfully rehabilitated can successfully manage the tasks of motherhood. Nursing, dressing and bathing an infant can be facilitated by simple adaptations. 
These workers reported no knowledge of neglected children by paraplegic mothers.

Richards (1982) reported children whose spinal cord injured parents were aged 25 to 40 years old most often developed problems. Commonly, these were teenagers who felt insecure. The most frequently noted problem was truancy from school. Most children were reported to cope well.

\section{The psychiatrist in the spinal injuries unit}

\section{The role of the psychiatrist}

The management of patients with spinal cord injury requires a multi-disciplinary team approach. What is the unique role of the psychiatrist in a team comprising medical practitioners, physio and occupational therapists, social workers, psychologists and nursing staff? The psychiatrist has a firm biomedical base, and a knowledge of psychosocial issues and is able to conceptualise ways in which these varying approaches can be synthesised (German, 1980).

The clinical method of the psychiatrist differs from that of other medical practitioners. The psychiatric examination includes the mental status examination, the physical examination and examination of the doctor-patient relationship. The psychiatrist's skill in mental status examination distinguishes him from both his medical and non-medical colleagues (Kalucy, 1980). Aspects of phenomenology (descriptive) and psychodynamics (explanatory) are examined. Observed phenomena include not only the patients behaviour but also that of the psychiatrist and other staff. All this data is used to generate explanatory hypotheses. The psychiatrist is also skilled in neurochemical and neuropharmacological concepts (Roth, 1982) important both for explanation of behaviour and for treatment of specific disturbances.

\section{Assessment and treatment of patients}

Initial assessment of the spinal cord injured patient has several functions (Stewart 1977a). Early and routine assessment of patients establishes the psychiatrist as a member of the spinal injury unit treatment team. During the initial interview, the focus is on assessment of the patient's personality and coping mechanisms. The injury may reduce the effectiveness of the patient's habitual coping strategies. This is particularly so for patients who physically act out to reduce tension. The psychiatrist may provide a hypothesis concerning the patient's psychosocial adjustment and likely potential problems. Knowledge of coping strategies used to deal with past stress enables staff to work more effectively with the patient in dealing with the stress of the spinal cord injury.

All patients with a pre-existing psychiatric disorder should be seen by the psychiatrist and treated as appropriate for that disorder. A history of suicide attempt necessitates early psychiatric involvement. Patients with a past history of depression, particularly those in whom the spinal cord injury was the result of suicide attempt may present particular management problems. Patients who have been depressed in the past are more likely to become depressed following spinal cord injury (Katz, et al., 1979). The use of tricyclic antidepressants or 
electroconvulsive therapy may be indicated (Hohmann, 1975).

Frequently, patients with spinal cord injury have pre-existing personality problems. Impulsive acts and risk taking behaviour may result in spinal cord injury. Many road accident victims have aggressive personality traits or a history of alcohol and drug abuse (Whitlock, 1971). Individuals with antisocial personality traits may have particular difficulty adjusting to their injury.

\section{Psychotherapy}

Appropriate psychotherapeutic management of the losses of the spinal cord injured patient relies on the principles of grief work. The mourning processes for those with spinal cord injury differ from bereavement. The loss must be renegotiated following many experiences. There are no established rituals as in death. The general aim is to promote a normal response. The patient should be supported and encouraged to express feelings of sadness, anger and guilt, and to go over memories and feelings of times prior to the accident. (Stein, et al. 1969).

The psychiatrist may encounter particular difficulties in treating the spinal cord injured patient. Denial may be prominent and prolonged. Families may collude with the patients denial particularly when their own need to deny is strong. The psychiatrist should encourage family members to communicate and share their feelings with the patient allowing beneficial mutual support.

The patient's anger may be extreme and is often displaced on to family and staff. Attention seeking angry behaviour may be reduced by giving the patient the support and recognition he needs. Firmness and limit setting will help the patient to gain impulse control.

Depression may be a chronic defence against confronting the disability of spinal cord injury. Psychiatrists should be wary of ascribing depression to the work of mourning and thus colluding with the patient in avoiding confronting the reality of his disability.

\section{Pharmacology}

Antidepressant and antipsychotic medication may be used in spinal cord injured patients, but side effects may be particularly troublesome. (Stewart 977a). Anticholinergic side effects may interfere with reflex bladder functioning. The alphaadrenergic blocking effect of medication may cause marked hypotension in patients with injury at or above $\mathrm{T}_{4}$ due to disruption of the thoraco-lumbar sympathetic outflow. The new bicyclic or tetracyclic antidepressants and the piperazine phenothiazines are less likely to cause such problems. Alprazolam, a triazolobenzodiazepine, recently shown to be effective in the treatment of depression (Feighner, 1982) does not have these side effects and may be of particular value.

\section{Intervention with staff}

Staff have prolonged contact with the patient and a major impact on the patient's adjustment. Work with severely disabled persons produces major stress. Constant exposure to physical disability may be emotionally overwhelming and threatening to a person's own sense of intactness. (Stewart 1977a). Staff are often the focus 
of the patient's angry feelings. Depression in the patient may evoke similar feelings in the staff. The physical injury, the basis of the patient's depression, causes a feeling of helplessness which may be projected to staff. This may give rise to anger which is displaced to others including patients. Alternatively, feelings of helplessness may be countered by defensive over-protection or rejection of patients (Stewart, 1977a). Too much may be done for the patient or excessive unrealistic demands of the patient may be made by staff. The psychiatrist should be alert to this and intervene where appropriate. Regressed and demanding behaviour of patients may also cause angry feelings in staff towards the patient. Staff may identify with the patient's feelings of outrage and experience their own anger in relation to the injury. Many staff working with spinal cord injured patients are in the same age range and identify strongly with the patient. The closer in age and life circumstances the staff member is to the patient, the closer and more threatening their identification.

Methods of dealing with stress include cognitive approaches such as inservice training programmes (Gunther, 1977). Education about spinal cord injury is an important coping strategy for staff. Ventilation of feelings such as anger, depression, and helplessness by staff should be encouraged. Structured staff sessions will help staff to realise the normality and acceptability of such feelings. Such meetings also allow them to share distress and angry feelings and gain insight from them (Tucker, 1980).

Within the spinal cord injury unit staff tensions may lead to scapegoating of particular patients. Those most prone to scapegoating include patients with problems of alcoholism or drug abuse or patients with psychiatric disorders. This may be expressed in disguised form such as pessimism about the quality of life of a particular patient. Appropriate interpretation and refocusing of concern usually resolves such problems.

\section{Intervention with patient's families}

In the first few days following injury families may experience a greater sense of helplessness than patients. Facilitating communication of the patient's and family's needs and promoting the ventilation of feelings may reduce the family's turmoil. Excessive hovering or avoidance of the patient may indicate difficulty of family coping mechanisms. The importance of regular but limited visits to reassure the patient of the family's interest and well being must be emphasised.

Denial of the injury by the family members may be prominent. The patient and family should be encouraged to share feelings regarding the injury. Psychiatrists should provide explanation, understanding and support. Families should be reassured of the normality of their own feelings of rage and resentment and should be encouraged to ventilate such feelings with the psychiatrist. Anger accompanied by guilt may be felt towards the patient if he contributed to the circumstances of the injury. Unhappy pre-existing relationships may result in guilt and fear, and shame of showing anger.

The psychiatrist should assist in organising family related services which operate from a developmental perspective. Both short term adjustment and chronic adaptation to the injury must be considered. Developmental needs of all family members should be assessed and periodically reviewed. 


\section{Conclusions}

The sequelae of spinal cord injury necessitate major psychosocial change for the injured patient and his family. Problems encountered may cause or be exacerbated by psychological difficulties.

Initial psychological problems following spinal cord injury are well defined. These include anxiety, lack of awareness of injury and impairment of conscious state, particularly due to sensory deprivation. Difficulties encountered during rehabilitation and long term adjustment have been less systematically studied and are less well understood.

Several authors have described distinct phases of adjustment to spinal cord injury. These are presumed to be normal and to occur in most patients. Many of these are modelled on the grief response. No controlled studies have documented these phases. It is commonly assumed that most patients with traumatic spinal cord injury will eventually experience depression. Only a few clinical studies have specifically assessed depression in spinal cord injured patients. These studies suggest depression occurs in a minority of such patients but at a greater rate than in the general population. Long-term follow-up studies have shown suicide occurs at a greater rate in patients with spinal cord injury than in the general population. Suicide and self-neglect may be the consequences of unrecognised and untreated depressive illness.

Most studies have assessed only the response of patients to their injury. Little information documenting the manner in which spinal cord injury influences marital relationships or the children of injured parents is available.

The majority of hypothesised psychological sequelae discussed in the literature have not been supported by systematic clinical investigations. Assumptions concerning such sequelae may have important implications for both short and long term treatment of patients with spinal cord injury. Further study of the psychological response of spinal cord injured patients and their families is indicated.

\section{Résumé}

Une blessure de la moelle épinière reproduit des conditions de détresse et d'incapacité immediates et de long terme. Liaison avec psychiatre peut jouer un rôle importand dans la conduite des problèms du patient souffrant d'une moelle épinière endommagée, de sa famille, et de l'équipe médicale. Des problèmes peuvent être causés ou aggravés par les difficultés psychologiques. Des problèmes se produisant pendant la réhabilitation et l'ajustement à long terme n'ont pa été étudié systematiquement.

Plusiers suppositions concernant les effets psychologiques à la blessure sont faits. Ces suppositions sont d'importance pour le traitement immediat et de long terme de patients. Cette étude examine certains aspects du problèms.

\section{Zusammenfassung}

Ruckenmarkverletzungen können sofortige und langhaltige Anstrengungen herausbrengen. Zusammenarbeit mit einem Psychiater kann eine wichtige Rolle spielen in der behandlung per Problemen des Kranken, seiner Familie und der medizinische Gruppe. Psychologische Schwerigkeien können Problemen verursachen und verschlimmern für den Kranken. Problemen die verkommen wahrend der Rehabilitierung und Anpassung wurden noch nicht systematisch studiert. Viele Veraussetzungen welche betreffen die psychologische Reactionen zu Verletzung waren gemacht. Solche Veraussetzungen haben wichtige Bedeutungen für der sofortiger wieh auch der langhaltiger Behandlung der Patienten. Diese Studie untersucht einige Aspecte in diesem Gebiete. 


\section{References}

Berger S, Garrett J 1952 Psychological problems of the paraplegic patient. Journal of Rehabilitation 18:15-17

Bors E 1951 Phantom limbs with spinal cord injury. Archives of Neurology and Psychiatry 66:610-631

BraCKen MB, Shepard MJ 1980 Coping and adaptation following acute spinal injury. A theoretical analysis. Paraplegia 18:74-85

Cogswell BE 1968 Self-socialisation-The adjustment of paraplegics in the community. Journal of Rehabilitation 34:11-13

COMARR AE 1962 Marriage and divorce among patients with spinal cord injury. International Journal of Indian Medical Profession 4353-4359

CONOMY J 1973 Disorders of body image after spinal cord injury. Neurology 23:842-850

Crewe NM, Athelston GT, KRUMBerger J 1979 Spinal cord injury: A comparison of preinjury and postinjury marriages. Archives of Physical Medicine and Rehabilitation 60:252-256

Davis R 1975 Pain and suffering following spinal cord injury. Clinical Orthopedics and Related Research 112:76-80

Elton D, Stanley G, Burrows G 1983 Psychological control of pain. Grune and Stratton, pp. $25-44$

ENGEL GL 1959 Psychogenic pain and the pain prone patient. American Journal of Medicine 21:899-918

ENGEL GL 1962 Psychological development in health and disease. W. B. Saunders Company, pp. 288-305

ERICKSON EH Childhood and Society. Norton, New York 1965. pp. 222-251

FEIGHNER J Benzodiazepines as antidepressants. In: Ban T (Ed) Modern Problems of Pharmacopsychiatry. Basal S. Kruger 1982. 18:196-212

FELTON JS, LitMAN M 1965 Study of employment of 222 men with spinal cord injury. Archives of Physical Medicine and Rehabilitation 46:809-814

Fullerton DT, Harvey RF, Klein MH, Howell T 1981 Psychiatric disorders in patients with spinal cord injuries. Archives of General Psychiatry 38:1369-71

German A 1980 The shaping of a psychiatrist. Australian and New Zealand Journal of Psychiatry 14:291-298

GUNTHER M Emotional aspects in: spinal cord injuries. 1969. Ed. R. Reuge, Springfield Ill. Charles C. Thomas pp. 127-142

GUNTHER MS 1977 The threatened staff: a psychoanalytic contribution to medical psychology. Comprehensive Psychiatry 18:385-394

Guttmann L 1964-65 Married life of paraplegics and tetraplegics. Paraplegia 2:182-188

GutTMANN L Spinal cord injuries-comprehensive management and research. Blackwell Scientific Publications Oxford 1976. pp. 42-54

Harris P, Patel S, Greer W, Naughton J 1973 Psychological and social reactions to acute spinal paralysis. Paraplegia 11:132-136

Heilporn A, NoEl G 1968 Reflections on the consciousness of disability and somatognosis in cases of acute spinal injuries. Paraplegia 6:122-27

Hopkins G 1971 Patterns of self destruction among the orthopedically disabled. Rehabilitation Research and Practice Review 3:5-16

HoHMANN G 1975 Psychological aspects of treatment and rehabilitation of the spinal injured person. Clinical Orthopedics 112:81-88

KalUCY R 1980 Commentary on "Why Psychiatry is a Branch of Medicine". Australian and New Zealand Journal of Psychiatry 14:279-290

Kaplan L, Powell BR, Grynbaum BB, Rush HA Comprehensive follow-up study of spinal cord dysfunction and its resultant disabilities 1966. New York Institute of Rehabilitation Medicine, New York University Medical Centre. pp. 27-35

Katz V, Gordon R, Iverson D, MYers SJ 1978-79 Past history and degree of depression in paraplegic individuals. Paraplegia 16:8-14

Kemp G, Vash C 1971 Productivity after injury in a sample of spinal cord injured persons. A pilot study. Journal of Chronic Disease 24:259-275

KERR W, ThOMpson M 1972 Acceptance of disability of sudden onset in paraplegia. Paraplegia 10:94-102

LAwson N 1978 Significant events in the rehabilitation process: The spinal cord patients point of view. Archives of Physical Medicine and Rehabilitation 59:573-579

LIPOWSKI ZJ 1974 Consultation-liaison psychiatry: An overview. American Journal of Psychiatry 131:623-630

Mueller AD, Thompson CE 1950 Psychological aspects of the problems in spinal cord injuries. Occupational Therapy \& Rehabilitation 29:86-95 
NAGLER B 1950 Psychiatric aspects of cord injury. American Journal of Psychiatry 107:49-55

NiCKERSON E 1971 Some correlates of adjustment by paraplegics. Perceptual and Motor Skills 32:11-23

NyGuist R, Bors E 1967 Mortality and survival in traumatic myclopathy during 19 years from 1946-1965. Paraplegia 5:22-48

Pilowsky I, Bassett DG 1982 Pain and depression. British Journal of Psychiatry 141:30-36

Pinkerton AC, Griffin ML 1983 Rehabilitation outcomes in females with spinal cord injury: A follow-up study. Paraplegia 21:166-175

RICHARDS B 1982 A social and psychological study of 166 spinal cord injured patients from Queensland. Paraplegia 20:90-96

Richards J, HiRT M, Melamedi L 1982 Spinal cord injury: a sensory restriction perspective. Archives of Physical Medicine and Rehabilitation 63:195-199

ROBERTS AH 1976 Spinal cord injury-some psychological considerations. Minnesota Medicine 55:1115-1117

RoTH M Future developments in psychiatry. In: Future directions for psychiatric research. Melbourne Health Commission of Victoria publication No. 10, 1982. pp. 1-8

SILLER J 1969 Psychological situation of the disabled with spinal cord injuries. Rehabilitation Literature 30:290-96

Solomon P, KLEEMAN ST Sensory deprivation. In: Comprehensive Textbook of Psychiatry 1985. IV Ed. Kaplan H. I., Sadock, B. J. pp. 621-626

STEIN E, MURDOCH ?, MACLEOD J 1969 Brief psychotherapy of psychiatric reactions to physical illness. American Journal of Psychiatry 8:76-83

STEWART TD 1977a Spinal cord injury: a role for the psychiatrist. American Journal of Psychiatry 134:538-541

STEWART TD 1977b Coping behaviour and the moratorium following spinal cord injury. Paraplegia 15:338-342

Steinglass P, Temple S, Lisman SA, Reiss D 1982 Coping with spinal cord injury. The family perspective. General Hospital Psychiatry 4:259-264

Strain JH, Gross S. Psychological care of the medically ill. A primer in liaison psychiatry. 1975. Appleton-Century-Crofts/New York pp. 23-37

ThORN DA, VON SALZEN CF, Frommer A 1964 Psychological aspects of the paraplegic patients. Medical Clinics of North America 30:473-481

TrieschmanN RB Spinal cord injuries. Psychological, social and vocational adjustment. Pergamon Press, 1981. pp. 35-86

TUCKER SJ 1980 The psychology of spinal cord injury: patient staff interaction. Rehabilitation Literature 41:114-119

TURK R, TURK M, Assejev V 1983 The female paraplegic and mother-child relations. Paraplegia 21:186-191

VERWOERDT A 1972 Psychopathological responses to the stress of physical illness. In: Psychosocial aspects of physical illness. Ed. Lipowski, Z. J. Vol. 8 of Advances in Psychosomatic Medicine Series. S. Krager Basel

WEINER M, LovitT R 1979 Conservation-withdrawal versus depression. General Hospital Psychiatry 4:347-349

WHITLOCK JA Death on the road: A study in social violence. Tavistock Publications in association with Hicks, Smith \& Sons London 1971. p. 212-214

Wilcox N, Stauffer E 1972 Follow-up of 423 consecutive patients admitted to the spinal cord centre Rancho Los Amigos Hospital, 1 January to 31 December, 1967. Paraplegia 10:115-122

Witthower E, Gingras G, Megler L, Widgor B, Lepine A 1954 A combined psychosocial study of spinal cord lessons. Canadian Medical Journal Association Journal 71:109-15

WoOdrich F, Patterson JB 1983 Variables related to acceptance of disability in persons with spinal cord injuries. Journal of Rehabilitation 49:26-30 